\title{
AVALIAÇÃO ECONÔMICO-FINANCEIRA DA MARCA VARIG
}

\section{ECONOMIC AND FINANCIAL EVALUATION OF THE BRAND VARIG}

\author{
Ana Cristina Leite Costa Issa'; Heloisa Márcia Pires² \\ 'Neoenergia S.A. - Rio de Janeiro - Brasil \\ aissa@neoenergia.com \\ ${ }^{2}$ Universidade Federal do Rio de Janeiro - UFRJ - Rio de Janeiro - Brasil \\ heloisam@pep.ufrj.br
}

\begin{abstract}
Resumo
Este trabalho tem o objetivo de calcular o valor da marca Varig considerando exclusivamente a perspectiva econômico-financeira. O método usado tem a premissa de que uma marca forte facilita a geração de uma margem operacional superior. Através da avaliação do fluxo de caixa descontado e da comparação de uma empresa, do mesmo setor, com valor de marca menos significante, chega-se ao resultado de US\$ 427 milhões, em 2003. A análise deste número com o obtido por meio de uma avaliação qualitativa, feita por empresa especializada, mostra grande discrepância. Tendo em vista que a Varig tem tido fracos resultados financeiros, mas detém a maior parcela do mercado brasileiro de aviação comercial regular, questiona-se a necessidade de aprimoramento do modelo quantitativo com a adição de variável qualitativa.
\end{abstract}

Palavras-chave: Aviação civil, Valor de marca, Fluxo de caixa descontado.

\section{Introdução}

A onda de fusões, aquisições e privatizações que inundou a economia brasileira no final da década de 80 produziu, entre seus efeitos colaterais, a descoberta de que a marca é um patrimônio muito mais valioso do que imaginavam as empresas nacionais. Seguindo um processo adotado nos Estados Unidos e na Europa nas últimas décadas, as companhias nacionais deixaram em segundo plano o valor de seus bens materiais para aferir o valor monetário de suas marcas e outros bens considerados ativos intangíveis. Segundo Lima (2003) "depois que o capital e a tecnologia ficaram acessíveis a todos, só existe uma forma de se diferenciar, a marca. (...) a lembrança da marca é só um dos componentes do seu valor. Ela só tem efetivamente algum valor de mercado se leva ao que de fato interessa: aos lucros". A maioria do esforço de avaliação de marcas, com relativa assiduidade, é feita apenas quando acontece uma operação de venda de empresa. Porém, a importância de uma avaliação de marcas não se limita à compra e venda de companhias, pois esta pode ser de extrema eficácia em decisões gerenciais e estratégicas, em securitizações e royalties, 
como também em processos de concordatas e/ ou falências. Muitas vezes, avaliar e definir o valor das marcas é matéria confundida com definir o valor das empresas, postura certamente inadequada.

O desenvolvimento da idéia de avaliação monetária de uma marca passou do antigo sistema de apuração, que levava em consideração fatores externos como a participação de mercado do produto e grau de lembrança espontânea por parte do consumidor e foi substituído por um intrincado esquema de apuração da influência da marca dentro da estrutura financeira das companhias, através da mensuração tanto dos ativos tangíveis como dos ativos intangíveis ligados à proprietária da marca. A forte competição no mercado e a expectativa potencial de lucros futuros acima do esperado respaldam a avaliação dos intangíveis. Neste ambiente, a contabilidade tem como desafio o tratamento a ser dado a estes ativos. Entretanto, ainda não são muitas as companhias nacionais que vêem com simpatia o novo modelo, principalmente no que se refere à abertura dos números. "Mas a chegada de mais multinacionais, acostumadas a este processo no exterior, está divulgando rapidamente os benefícios que o sistema proporciona” (Lima, 2003).

Este trabalho tem como objetivo quantificar o valor da marca Varig. A escolha desta empresa se deve a ela ser líder no mercado brasileiro de aviação regular comercial, estar em atuação por volta de 80 anos e realizar negócios no Brasil e no exterior. Estes indicadores mostram que a empresa tem sido importante para o consumidor brasileiro, mas nos últimos anos apresentou um fraco desempenho financeiro. Assim, foi escolhido um modelo de avaliação de marca que leva em conta somente dados econômico-financeiros, não incluindo, portanto, dados qualitativos, para verificar a aderência do modelo numa situação de adversidade de resultados financeiros.

Este estudo inicia-se com o conceito de marca e seus determinantes. A seção 3 introduz as variáveis utilizadas em avaliação de marca. Na seção 4, descrevemos avaliação de investimentos e é definida a metodologia do estudo de caso. Este é mostrado na seção 5. Após, são discutidos os resultados e segue-se para as conclusões.

\section{O que é marca}

A marca carrega consigo uma identidade, uma forma de expressão que faz parte do cotidiano das pessoas, por elas terem em mente um nome ao lembrar de um produto ou serviço e representa o jeito de ser da empresa e seus princípios. Além disso, as empresas utilizam-se das marcas em suas ações estratégicas para melhor posicionar o seu bem ou serviço na tentativa de se obter sucesso no mercado. Deste modo, a partir do século XX, a marca passou não só a distinguir um produto dos demais como também representa uma alavancagem de desempenho econômico diante de processos de aquisição, transmitindo toda sua força durante as negociações. Nos dias atuais, as pessoas também depositam uma enorme confiança em determinadas marcas, tornando-se 
fiéis a elas, pois crêem que os valores da empresa estão expressos nos seus produtos no que diz respeito à responsabilidade social, credibilidade e qualidade. A empresa deve fazer com que seus consumidores tornem-se fiéis à marca e não apenas ao produto, pois, caso a organização tenha que descontinuar uma mercadoria, o cliente poderá se adaptar a um outro produto da empresa de mesma marca.

\section{Avaliação de marca}

A avaliação da marca de um produto tem o enfoque básico de determinar o valor que a mesma agrega ao faturamento ou, ainda, o quanto à marca propicia ao resultado líquido dos produtos caso os mesmos não apresentassem as respectivas marcas. Em outras palavras, seria como determinar o benefício que uma certa marca propicia a uma cadeia produtiva ou quanto uma marca consolidada e bem construída ao longo de um certo período proporciona de lucros. Os primeiros modelos desenvolvidos para avaliação de marcas surgiram na década de 80. Estes modelos, de uma forma geral, apresentam uma grande subjetividade em seus resultados já que, em sua maioria, utilizam critérios qualitativos para determinar o valor da marca.

A Interbrand é uma consultoria britânica que desde sua fundação, em 1974, se especializou no fornecimento de serviços relacionados à marca tais como avaliação, criação e administração da marca. A consultoria realiza anualmente o estudo "The World's Greatest Brands" que delimita as 100 maiores marcas mundiais pontuando sete aspectos da marca para a sua avaliação. São eles: 1) Liderança - as marcas com maiores quotas de mercado são mais valorizadas; 2) Longevidade - as marcas com maior tradição, ou seja, quanto mais prolongada for a existência da marca em seu setor de atuação, terão mais chances de obter fidelidade e lembrança espontânea dos consumidores; 3) Situação do mercado - as marcas em mercado de grande crescimento, mais promissoras, são mais valorizadas; 4) Internacionalização - as marcas com maior grau de penetração em outros países, sem ser o de sua origem, possuem maior valor; 5) Tendência - a evolução positiva das vendas da marca no tempo reflete uma posição mais forte, sendo mais valorizadas; 6) Apoio - as marcas que continuam a ter forte apoio em termos de ações publicitárias são consideradas mais fortes; 7) Proteção - o nível de proteção legal e abrangência também entram como uma força da marca.

Desses, liderança e grau de internacionalização são fatores que pesam mais que outros. A liderança aumenta a capacidade que uma marca tem de influenciar o seu mercado, estabelecer preços, comandar a distribuição e dificultar a entrada de novos concorrentes. Quanto maior o grau de internacionalização, que uma marca confere, maiores serão suas vantagens competitivas. Isto possibilita, por exemplo, abrir novas frentes de consumo quando o mercado de origem estiver estagnado. 


\section{Avaliação de investimentos}

A avaliação de investimentos visa, através de técnicas e modelos, chegar a um "preço-justo" do ativo avaliado para a posterior análise de oportunidade de alocação de recursos nele. O mais importante, entretanto, no processo de avaliação de investimentos, é a busca pelo conhecimento das fontes de valor do ativo para que a estimativa de seu preço seja o mais justo possível, assim o investidor não deverá adquirir um ativo super avaliado. Segundo Damodaran (2003) "Em termos gerais são três as abordagens mais utilizadas para avaliação: a avaliação relativa, o método do fluxo de caixa descontado e a avaliação por direitos contingentes". O método do fluxo de caixa descontado, entretanto, é o mais reconhecido e utilizado para avaliar empresas. Isto porque, quando existe uma boa previsibilidade de fluxos de caixa futuros os resultados são mais confiáveis e precisos de valor. Simplificando, o valor do ativo deverá ser a função de três fatores: a expectativa dos fluxos de caixa gerados no futuro, o período em que os fluxos vão acontecer e o nível de incerteza a ele associados. Segundo Damodaran (2003) “tem sua fundamentação na regra de 'valor presente', onde o valor de qualquer ativo é o valor presente dos fluxos de caixa futuros dele esperados". A avaliação pode ser realizada por dois métodos diferentes: 1. avaliando-se apenas a participação acionária do negócio o chamado fluxo de caixa do acionista; 2. avaliando-se a empresa total, neste caso além da participação acionária avalia-se a participação dos demais detentores de direitos da empresa, é o chamado fluxo de caixa da empresa. Embora ambas as abordagens descontem fluxos de caixa esperados, os fluxos de caixa e taxas de desconto relevantes não são os mesmos em cada caminho. Mas, apesar dos valores encontrados em cada caso serem diferentes, "produzirão estimativas consistentes de valor, desde que o mesmo conjunto de pressuposições seja utilizado" (Damodaran, 2003).

\section{Estudo de caso}

Foi escolhido como setor de estudo o de aviação civil e dentro deste, foram selecionadas as empresas Varig e Tam, nos anos de 1999 a 2003. A Varig será a empresa de estudo para a aplicação do modelo de avaliação da marca, pois no mercado brasileiro é a companhia que tem os principais aspectos considerados pela Interbrand, ou seja, liderança e internacionalização. Além disto, a Varig é a empresa mais antiga do mercado de aviação no Brasil, tendo adicionalmente o aspecto estabilidade. A Tam será utilizada como exemplo para a determinação da margem operacional típica de empresas com um atributo da marca menos significante. A escolha da Tam como empresa de comparação é questionável, mas as limitações deste setor impuseram esta opção. Não existe outra empresa brasileira, de capital aberto, de transporte regular de passageiros, neste período de tempo, atuando no mercado. A hipótese de selecionar uma empresa de outro setor, ainda que 
possível, seria pior, porque envolveria outra indústria com diferentes peculiaridades. A coleta dos dados foi feita através da Comissão de Valores Mobiliários e diretamente nas empresas.

\subsection{Apresentação do modelo de avaliação de marcas}

O modelo utilizado foi proposto por Ozório (2003). Baseia-se na premissa de que o método do fluxo de caixa descontado poderia ser aplicado na avaliação de marcas. Dessa forma, poder-se-ia utilizar este método tanto para o cálculo do valor de uma empresa, ou unidades de negócios, quanto para projetos e, neste caso, para obter o valor da marca. A identificação do fluxo de caixa proveniente do gerenciamento da marca leva a utilização e análise dos atributos da marca e seus impactos nos fundamentos econômicos das empresas, verificando assim, que uma marca forte desempenha o papel de facilitador operacional, auxiliando e influenciando os consumidores em sua tomada de decisão (relativa à escolha de produtos e serviços). Em outras palavras, esses atributos têm a característica de acrescentar valor para a empresa, pela geração marginal de fluxo de caixa. Portanto, partindo do pressuposto de que empresas com marca forte produzem margens operacionais mais elevadas, o modelo visa avaliar a marca através do fluxo de caixa gerado pelo excedente de margem operacional através do método do fluxo de caixa descontado.

\subsection{Aplicação do modelo de avaliação da marca}

\subsubsection{Margem operacional}

A margem operacional, para esta análise, será a relação entre:

Margem operacional $(\%)=$ Receita operacional líquida $(\mathrm{ROL}) /$ Resultado do serviço

Onde: Resultado do serviço $=$ ROL (-) Custo do serviço prestado (-) Despesas operacionais

O Quadro 1 mostra o valor obtido para as margens operacionais nos últimos 5 anos para as empresas Varig e Tam. Para estimar a taxa média de crescimento futuro das margens operacionais será utilizada a média geométrica que, segundo Damodaran (2003) "é uma medida claramente mais precisa do crescimento real, especialmente se o crescimento anual tiver sido inconstante".

\begin{tabular}{cccccc}
\multicolumn{6}{c}{ Quadro 1 - Valores realizados da margem operacional (\%) } \\
\hline Empresas & 1999 & 2000 & 2001 & 2002 & 2003 \\
\hline Varing & 2,84 & 4,48 & $-3,04$ & 0,70 & 4,90 \\
TAM & 4,76 & 11,31 & 9,22 & 15,87 & 6,63 \\
\hline
\end{tabular}


E:

$$
\text { Varig }=\left(\frac{4,90 \%}{2,84 \%}\right)^{1 / 5}-1=11,55 \% \quad \text { Tam }=\left(\frac{6,63 \%}{4,76 \%}\right)^{1 / 5}-1=6,85 \%
$$

Para efeito das projeções, utilizaremos como margem típica de empresa com atributo da marca o valor de $11,55 \%$ e para a empresa com menor atributo da marca o valor de $6,85 \%$.

\subsubsection{Custo de capital}

Etapa 1 - O primeiro passo para o cálculo do custo de capital (WACC) é determinar a participação de capital de terceiros e do capital próprio na companhia, para se ponderar o "peso" destes itens teriam na taxa calculada. Para este cálculo, usamos como medida o nível de alavancagem financeira da empresa, mostrado no Quadro 2.

Quadro 2 - Participação do capital de terceiros e do capital próprio da Varig (\%)

\begin{tabular}{cccccc}
\hline Anos & 1999 & 2000 & 2001 & 2002 & 2003 \\
\hline Dívida onerosa/Dívida onerosa + PL & 98 & 109 & 871 & -109 & -74 \\
\hline
\end{tabular}

Analisando os resultados do quadro 2, verificamos que a participação do capital próprio (PL) no financiamento da Varig muda de configuração nos anos analisados. Em 1999, o PL era muito pequeno em relação à dívida onerosa. No período de 2000/2001 o PL ficou negativo passando a passivo a descoberto, porém o valor, em módulo, era menor do que a dívida. Nos anos de 2002/2003 a empresa continua apresentando passivo a descoberto, mas o valor, em módulo, é maior do que o valor da dívida. Portanto, para o cálculo da taxa de desconto, será considerada como zero a participação do capital próprio.

Etapa 2 - O cálculo do custo médio ponderado de capital (WACC) da Varig. O Quadro 3 mostra o cálculo. As premissas de cálculo encontram-se no Anexo 1.

Quadro 3 - Avaliação econômico-financeira da marca VARING

\begin{tabular}{|c|c|}
\hline Variáveis & Valores \\
\hline Participação capital de terceiros & $100,00 \%$ \\
\hline Custo capital de terceiros sem inflação (CCT) & $26,48 \%$ \\
\hline Impostos & $34,00 \%$ \\
\hline Participação do capital próprio & $0,00 \%$ \\
\hline Custo médio ponderado de capital - WACC $(1)$ & $17,48 \%$ \\
\hline
\end{tabular}

(1) $\mathrm{WACC}=((100 \% * 26,48 \%) *(1-34 \%))$ 


\subsubsection{Fluxo de Caixa}

Serão apresentados dois fluxos de caixa para o cálculo do valor da marca. Para cada fluxo apurado será calculado o valor da empresa e a diferença entre estes dois valores determinará o valor da marca Varig.

Figura 1 - Resultado do Serviço (R\$ mil)

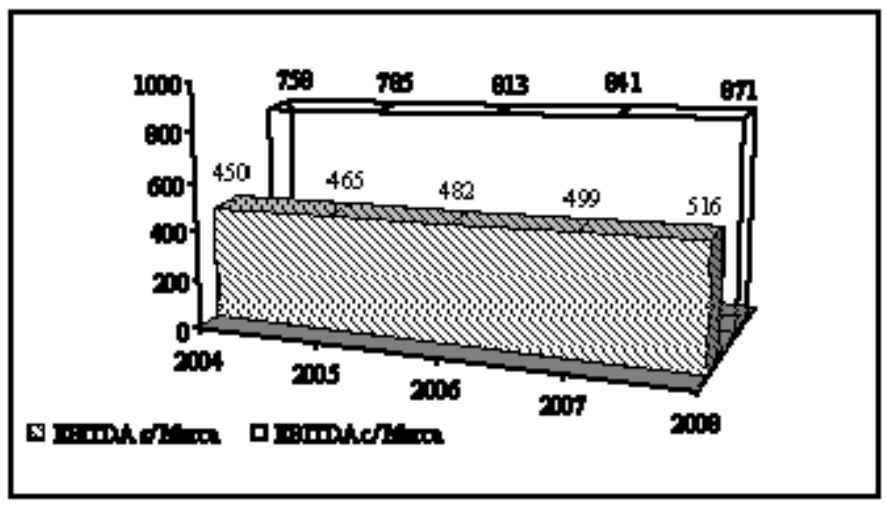

Os fluxos partem da mesma base, a receita operacional bruta (ROB) da Varig realizada no ano de 2003. Sobre esta receita, foi utilizado um percentual de crescimento de $3,5 \%$ ao ano, equivalente as projeções de crescimento real do PIB para o longo prazo (até 2008). Para a projeção de 2009 em diante (perpetuidade) foi considerada a mesma taxa de 3,5\%. Destes valores, são deduzidos os impostos faturados, que foram calculados partindo do valor realizado de 2003 da Varig acrescentando-se um percentual de crescimento de 2,3\% ao ano, calculado a partir da média dos anos de 1999 a 2003 (Quadro 4 e 5). Até este ponto, os fluxos são exatamente iguais. O que diferencia os dois fluxos, a partir deste ponto, é o percentual da ROL que corresponde ao valor agregado da marca na geração da receita, este percentual é a margem operacional calculada para cada tipo de empresa (11,55\% com marca e 6,85\% sem marca). Com isso, são obtidos dois fluxos de resultado do serviço (EBITDA), como mostra a figura 1. As demais premissas de projeção do fluxo são: 1) Investimentos - considerou-se um valor de R 100 milhões para todo o horizonte de projeção; 2) Depreciação - crescimento de 3,5\% aplicado sobre o último período realizado da Varig (2003); 3) Variação do capital de giro - utilizado o percentual de crescimento de 3,5\% sobre a variação do capital de giro dos anos 2002 e 2003 da Varig. Com isso, foram obtidos 2 fluxos de caixa, o com marca (Quadro 4) e o sem marca (Quadro 5): 
Quadro 4 - Fluxo com marca

\begin{tabular}{|c|c|c|c|c|c|c|}
\hline & \multirow{2}{*}{$\begin{array}{l}2003 \\
\text { Realizado* }\end{array}$} & 2004 & 2005 & 2006 & 2007 & 2008 \\
\hline & & \multicolumn{5}{|c|}{ Projetado* } \\
\hline Receita operacional bruta & 6.469 & 6.696 & 6.930 & 7.173 & 7.424 & 7.684 \\
\hline (-) Impostos faturados & 130 & 133 & 136 & 139 & 142 & 146 \\
\hline Receita operacional liquida & 6.340 & 6.563 & 6.794 & 7.034 & 7.281 & 7.538 \\
\hline EBITDA & 323 & 758 & 785 & 813 & 841 & 871 \\
\hline $\operatorname{EBITDA}^{*}(1-\mathrm{t})$ & & 500 & 518 & 536 & 555 & 575 \\
\hline (-) Investimentos & & 100 & 100 & 100 & 100 & 100 \\
\hline (+) Depreciação e amortização & 32 & 33 & 34 & 35 & 36 & 37 \\
\hline (-) Variação do capital de giro & 212 & 219 & 227 & 235 & 243 & 252 \\
\hline Subtotal & 350 & 214 & 225 & 236 & 248 & 260 \\
\hline $\begin{array}{l}\text { Valor residual } \\
\text { FCFF }\end{array}$ & 350 & 214 & 225 & 236 & 248 & $\begin{array}{l}1.539 \\
1.799 \\
\end{array}$ \\
\hline $\begin{array}{l}\text { WACC } \\
\text { VALOR DA EMPRESA }\end{array}$ & $\begin{array}{l}17,48 \% \\
1.424\end{array}$ & & & & & \\
\hline
\end{tabular}

$\left({ }^{*}\right)$ Valores em RS mil.

Quadro 5 - Fluxo sem marca

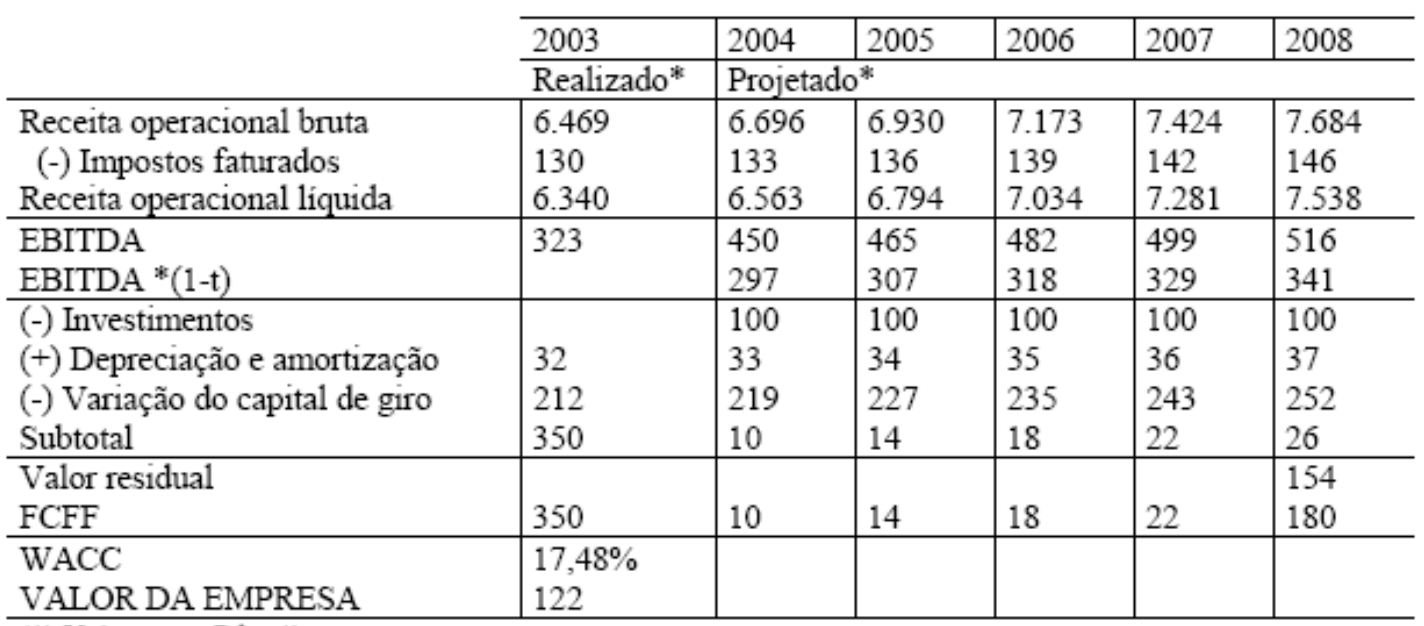

$\left({ }^{*}\right)$ Valores em $\mathrm{RS}$ mil.

\subsubsection{O valor da marca}

O valor da marca Varig foi, portanto, estimado por diferença entre o valor da empresa com marca e o valor da empresa sem marca, o qual é mostrado no Quadro 6:

Quadro 6 - Valor da marca

\begin{tabular}{lll}
\hline Valor da empresa com marca & 1.424 & em milhares de Reais \\
(-) Valor da empresa sem marca & 122 & em milhares de Reais \\
= VALOR DA MARCA & 1.302 & em milhares de Reais \\
& 427 & em milhares de Dólares* \\
\hline
\end{tabular}

* Foi considerado o dólar médio de 2003 (RS 3,05) para a conversão. 


\section{Análise dos resultados}

Partindo das informações coletadas sobre as companhias, chegamos ao valor de $\mathrm{R} \$ 1.424$ milhões para o ativo da Varig e o valor de R\$ 122 milhões para o ativo da empresa com menor atributo da marca. A diferença entre os valores encontrados, R\$ 1.302 milhões, é o valor considerado da marca Varig, em 2003, o que corresponde a 16\% da receita líquida.

A Interbrand faz o ranking mundial das marcas mais valiosas, que é usado por muitas companhias para regular seu valor patrimonial. Desde 2001, vem elaborando a lista das " 12 principais marcas brasileiras". Em 2002, a Varig estava em sexto lugar com o valor de marca de US\$ 187 milhões. No entanto, em 2003, a Varig, segundo os resultados da Interbrand mostrados por Castanheira (2003), é uma das empresas que perdeu valor de marca.

Figura 2 - Lucro líquido da Varig (R\$ mm)

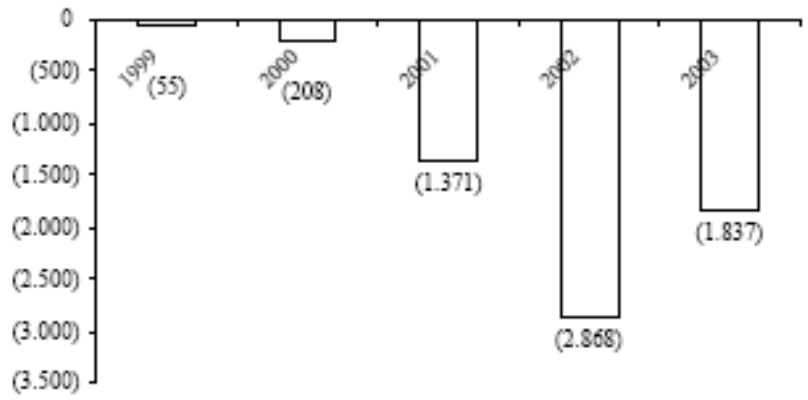

A Interbrand avalia o quanto à assinatura de uma empresa gera recursos para seus acionistas. A marca é vista da mesma forma como os demais ativos de um negócio. São utilizados indicadores de desempenho, de marketing, de receita, do lucro, do tamanho do setor e participação de mercado. Do resultado final, é descontado um valor, referente aos riscos que a companhia corre nos próximos anos. Esta parece ter sido a razão da empresa ter saído da lista. O resultado líquido da Varig (Figura 2) não tem sido positivo por longo tempo e o risco com relação a permanência da empresa no mercado tem crescido. Por outro lado, de acordo com o Anuário Estatístico do Transporte Aéreo de 2003, divulgado pelo Departamento de Aviação Civil (DAC), 42\% do tráfego aéreo internacional (partindo do Brasil), é composto por empresas brasileiras e deste montante, $35 \%$ pertencem somente a Varig. A sua participação de mercado, apesar do resultado financeiro ruim, continua alta. A empresa é preferência de escolha por parte de muitos consumidores brasileiros e ainda que sua imagem tenha se deteriorado permanece com uma atuação relevante. Ademais, como é possível uma marca valer tanto em um ano e no seguinte não valer mais nada? Assim, verificamos que parecem existir questões a serem levantadas com relação aos modelos de avaliação de marca. Possivelmente, no caso de empresas como a Varig, com alta participação de mercado, mas resultados financeiros insatisfatórios, seria necessário incluir alguma variável ao modelo quantitativo que ponderasse estes fatores. O importante, porém, independente do modelo utilizado, 
é reconhecer a importância que uma marca forte tem na criação de valor para uma empresa, seja através do melhor posicionamento de seus produtos/serviços, seja na expectativa potencial de lucros futuros para esta.

\section{Conclusão}

Este estudo quantificou o valor da marca Varig baseado exclusivamente em dados econômico-financeiros. Usando o método do fluxo de caixa descontado e outra empresa do setor para servir de comparação chegou-se no valor de US\$ 427 milhões para a marca Varig, em 2003. Concluímos que é possível quantificar o valor da marca quando partimos da premissa que marcas fortes atuam com uma margem operacional maior do que as empresas que não possuem este atributo. Além disso, questionou-se a limitação do modelo ser exclusivamente quantitativo, pois a análise indicou ser adequada a adição de uma variável qualitativa que aumentasse a robustez dos resultados.

\section{Referências}

DAMODARAN, A. Applied Corporate Finance: A User's Manual. Jonh Wiley \& Son’s, Inc. New York, 2003

LIMA, A. A.As mais valiosas marcas do Brasil, In: CASTANHEIRA, J. Revista Isto É Dinheiro. 04 de junho,. www.istoedinheiro.com.br, 2003

OZÓRIO, L. M. Avaliação de Marcas.Dissertação de Mestrado. Coppe, Universidade Federal do Rio de Janeiro. Rio de Janeiro, 2003

Demonstrações financeiras das empresas Varig e Tam. Comissão de Valores Mobiliários. www.cvm.gov.br

\section{Anexo 1 - Premissas de cálculo do custo médio ponderado de capital}

\begin{tabular}{l|l|l}
\hline Variáveis & Fonte e equações & Taxas \\
\hline $\begin{array}{l}\text { Certificado de depósito inter } \\
\text { bancário CDI }\end{array}$ & $\begin{array}{l}\text { Valor final de 2003. Fonte: } \\
\text { Gazeta Mercantil }\end{array}$ & $23,24 \%$ \\
\hline "Spread" * & & $15,00 \%$ \\
\hline $\begin{array}{l}\text { Custo de capital de terceiros com } \\
\text { inflação Brasil }\end{array}$ & (CDI + Spread) & $38,24 \%$ \\
\hline $\begin{array}{l}\text { Indice de preço ao consumidor } \\
\text { amplo IPCA }\end{array}$ & $\begin{array}{l}\text { Valor final de 2003. Fonte: } \\
\text { Gazeta Mercantil }\end{array}$ & $9,30 \%$ \\
\hline $\begin{array}{l}\text { Custo de capital de terceiros sem } \\
\text { inflação Brasil }\end{array}$ & & $26,48 \%$ \\
\hline
\end{tabular}

(*) Foi arbitrado o valor de $15 \%$ tendo em vista o endividamento da empresa e a ausência de capital próprio como fonte de financiamento. Esta estrutura de capital representa um alto nível de risco para o credor mesmo no caso da empresa fazer parte de uma indústria com a peculiaridade de ser estratégica para nação, envolvendo soberania e segurança nacional. O governo brasileiro, historicamente, tem tutelado o setor, em diversos e diferentes níveis. Portanto, a empresa 
não participa de um mercado competitivo tradicional, o que explica, em parte, a sua permanência no mercado mesmo no caso de ser arriscada.

\section{Dados completos do primeiro autor:}

Nome completo: Ana Cristina Leite Costa Issa

Filiação institucional: Neoenergia S.A. - Departamento de Planejamento e Controle

Função ou cargo ocupado: Analista de Planejamento e Controle Pleno

Endereço completo para correspondência (bairro, cidade, estado, país e CEP):

Telefones para contato: Praia de Botafogo, 148, apto. 701 - Botafogo -

Rio de Janeiro - RJ

CEP: $22250-040$

Fone: (21) 2551-3109

e-mail: aissa@neoenergia.com

Recebido para publicação em: 05/11/2005

Aceito para publicação em: 14/01/2006 